\title{
La privatización, sus formas y su proceso
}

\section{Introducción}

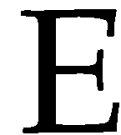

1 proceso de privatización en nuestro país parece un hecho irreversible, pues se ha tomado como una de las principales medidas económicas a ser implementadas por el actual gobierno en el próceso de modernización del Estado. Dado que el proceso de modernización es muy complicado y a la vez reviste importancia a nivel nacional, el presente artículo es un extracto del trabajo de graduación " El proceso de privatización en El Salvador: El caso de ANTEL y CEL “.

En este se presenta un acercamiento a la problemática del proceso de privatización, comenzando por conceptualizar este termino.

Con el propósito de tener un proceso medianamente exitoso, se esquematizan las etapas, con sus correspondientes pasos, que se recomienda siga un proceso de privatización.

Así como hay etapas a seguir, también se plantean los obstáculos que pueden presentarse al desarrollarlo, sobre todo en los países subdesarrollados. Tomando en cuenta estos obstáculos, se presentan las diferentes formas por las que se puede llegar a la privatización. Finalmente se presenta una propuesta alternativa para el proceso de privatización en ANTEL.

\section{Acercamiento al concepto de privatización}

\section{El concepto de privatización}

A la luz de los hechos históricos del pasado y presente siglo cabe preguntarse si la privatización es una teoría asentada en principios determinantes; si es un movimiento $u$ onda secular (propia de un siglo); o si es una práctica o medida económica en orden a determinado objetivo. 
La privatización ¿Es un medio o un fin por sí misma?, la pregunta presenta dos problemas:

a) El fin social de toda propiedad sea pública o privada

b) Las funciones propias del sector público (Estado) y del sector privado.

A la vez se integran dos enfoques: Un enfoque histórico de cómo ha funcionado la propiedad privada y cómo el Estado ha realizado sus funciones; otro enfoque de derecho que habla de cómo debían haber funcionado.

$\mathrm{Al}$ analizar los dos últimos siglos parecería que las imperfecciones y los abusos históricos de ambos modos de propiedad y de ambos sectores, - público y privado-, han generado cíclicamente posiciones o teorías enfrentadas.

El concepto de privatización difiere en función de la ideología o teoría que lo sustente. Se esquematizan algunas de las actuales interpretaciones y el concepto de privatización que se aplica en el presente trabajo:

A) Según el INCAE, la privatización es entendida como la transferencia al sector privado de actividades económicas de naturaleza privada, que actualmente están en manos del estado o administradas por instituciones descentralizadas. 1

B) Privatización es la transferencia de bienes y funciones de servicios del sector público al sector privado. 2

C) Privatizar es la estrategia para lograr la abundancia, generalizar, difundir los derechos de propiedad sobre todo tipo de bienes y servicios para que sean producidos por el mercado. 3

D) La privatización debe considerarse un programa estratégico del gobierno para reducir la participación del Estado en actividades, que por diversas razones deben ser competitivas, fortaleciendo así la economía de mercado. 4

Estas breves referencias parecen insistir en que ha habido una extralimitación de las funciones públicas, invadiendo responsabilidades del sector privado, (se habla de transferir propiedad, de menor participación del Estado en la actividad económica, de ventas de empresas estatales, etc.). Se percibe que el modo de propiedad o de administración viene determinado por las funciones propias de cada sector. Sin embargo, parece que en ambos modos de administración y propiedad, (pública o privada), no toca el carácter social.

La privatización es considerada como un fin para obtener un benefi- 
cio o lograr ciertos objetivos; sin embargo, cabe preguntarnos si la privatización:

a) ¿Es un fin y medio al mismo tiempo?

Es precisamente ambas cosas sin dejar de lado una, en función de la otra.

b) ¿No es simplemente un medio, sino que es un objetivo buscado por sí mismo como parte de una teoría?

Tomemos en cuenta que la privatización es una política por la cual se desea modernizar el sector público, incluida dentro de toda la concepción neoliberal.

c) ¿Es una imposición de las instituciones financieras internacionales con las que el gobierno está comprometido?

Es decir, ¿Estos procesos de privatización se llevan a cabo por presiones extranjeras que buscan modificar internamente la estructura económica de los países en vías de desarrollo?

Tomando en cuenta la visión de analistas, técnicos, economistas y de algunos políticos, se agrupan diversas justificaciones por las cuales se realiza la privatización, tomándose en cuenta cuatro áreas específicas:

a) Desde el punto de vista económico: se pretende lograr mayor eficiencia, menor control de precios, restablecer la competencia, entre otros.

b) Desde el punto de vista fiscal: se espera que por lo menos en el corto plazo los ingresos para el fisco sean elevados.

c) Desde el punto de vista político: se pretende la satisfacción del concepto del estado y sus funciones.

d) Desde el punto de vista social: se busca maximizar el beneficio de los consumidores y dar oportunidad a mayor parte de la población para que participe en el desarrollo de las actividades económicas.

Tomando en cuenta estas justificaciones, reflexionamos un poco sobre ellas:

La privatización no es solo un fin a conseguir para posteriormente pretender ciertos objetivos; la privatización debe ser mejor entendida, como un medio a través del cual se buscará el mayor bienestar social. No solo bienestar de un agente económico, sino el bienestar de la sociedad en general.

Es decir, debe haber: un mayor bienestar (eficiencia) de las funciones sociales que siempre debe seguir generando el Estado. 
Mayor bienestar (eficiencia económica) de parte del sector privado, que se presupone lo hará mejor.

Mayor bienestar de los usuarios finales, sin discriminación de ingresos, que demanden estos bienes y servicios.

El proceso de privatización, en cuanto se fundamenta en las normas del mercado, queda supeditado, a la vez, a las ventajas e imperfecciones que pueda presentar tanto el mercado nacional e internacional (globalización). Con la privatización es posible liberarse de las imperfecciones y trabas de la propiedad-administración del sector público; pero podemos enfrentarnos con las imperfecciones típicas de nuestra propiedad-administración privada (monopolios, duopolios, oligopolios y otras que puedan crearse en el tiempo). Este aspecto levanta cuestionamientos serios y plantea alternativas intermedias en cada uno de los casos. El problema fundamental es lograr una propiedad y administración social.

Tenemos como la misma sociedad busca recuperar el poder y la libertad que antes, ( en un momento dado) tenía y un medio para lograrlo sería la privatización; para ello es necesario que estos procesos se lleven a cabo de manera transparente procurando una participación real de la población; es decir, procurando una democratización, no solo de participar en las actividades productivas, creando nuevos empresarios y accionistas; sino también que esta democratización llegue al capital y la riqueza.

Hay que tomar en cuenta que si se desea el bienestar social, debe existir una sociedad organizada y ordenada de manera democrática y libre; pero también debe ser económicamente eficiente. No se debe perder de vista que actuamos de manera personal, individual; pero que pertenecemos a una sociedad y por tanto también tenemos obligaciones sociales.

Debemos actuar de manera libre, pero de forma responsable y eficiente para poder lograr el bienestar social, tomando en cuenta que este medio (la privatización) da pautas para hacerlo, cualquiera sea la forma por la cual se lleve a cabo.

\section{Etapas de la privatización}

Una vez preparado el campo para la privatización, se llevan a cabo las siguientes etapas, las cuales no constituyen una receta clásica, sino más bien constituyen un orden que han seguido algunos países en sus experiencias de privatización. Su aplicación será diferente para cada caso, dependerá entonces de la realidad propia de cada país, pero se reco- 
mienda desarrollar el proceso de privatización tomando en cuenta cada una de ellas.

Al desarrollar cada una de las etapas, deben ir implícitos los siguientes aspectos fundamentales:
a) Sencillez
b) Transparencia
c) Gradualidad

\subsection{Etapa I: Desarrollo institucional}

Esta primera etapa contiene cuatro pasos, los cuales sustentan las bases políticas y prácticas para iniciar la instrumentación del proceso de privatización.

1. Organización de las iniciativas de privatización.

En este paso desarrolla los principales objetivos que el gobierno se plantea lograr:

- Investigar y examinar la viabilidad del proceso de privatización.

- Desarrollar suficientes conocimientos, experiencia y confianza en el gobierno para elaborar objetivos viables, entre ellos oportunidades específicas de privatizar.

Inicialmente, en la formalización de los objetivos, el gobierno debe nombrar un alto funcionario, encargado de establecer las normas a seguir durante el desarrollo de proceso de privatización. Esta persona seleccionada debe gozar de ciertas características que lo identifiquen con los intereses sociales en general; ya que durante el proceso estará vinculado con el liderazgo político del gobiemo, e intervendrá regularmente en la toma de decisiones de alto nivel.

Respecto al personal y los recursos económicos necesarios para el proceso, serán asignados de acuerdo al contenido de los objetivos del gobierno.

Básicamente, deben existir grupos representativos de cada sector involucrado en el proceso que puedan ayudar a moldear la estructura e instrumentación de programa.

Deberá existir además un grupo asesor el cual juega un papel importante en todo proceso de privatización, capaz de ayudar en investigaciones, hacer recomendaciones sobre política, definir los procesos administrativos, establecer e identificar los objetivos de la privatización y supervisar sus iniciativas. 
2. Hacer un balance del contexto político:

Se deberá determinar en este paso, si la privatización permitirá que los líderes legislativos y ejecutivos manejen y supervisen mejor la producción y provisión de los servicios. Adicionalmente, se deberá examinar el impacto que el proceso de privatización tendrá en tres grupos principales:

a) Impacto del proceso de privatización en el público en general. Se deberá a considerar puntos como:

Mantener el control local.

Garantizar los intereses de la economía y la sociedad en oposición de los intereses monopólicos.

Garantizar que los precios y la calidad de los productos y servicios sean razonables y accesibles para toda la población.

Garantizar fuentes gubernamentales alternativas que compensen los servicios que puedan ser suspendidos.

b) Impacto del proceso de privatización en los empleados de gobierno. Se deberá considerar los siguientes puntos:

Presentar medidas que protejan los derechos, beneficios y oportunidades de trabajo de los empleados.

De no continuar trabajando con el gobierno, los empleados deberán tener preferencia de trabajo en el sector privado.

c) Impacto del proceso en el sector comercial:

Detallar claramente el porcentaje de inversión a la que tendrán acceso tanto las empresas nacionales como las extranjeras.

Determinar qué parte de la actividad comercial estará a disposición de las empresas locales, en oposición a las entidades no locales o extranjeras; cuáles ramas de trabajo recibirá cada sector(director o trabajador, calificado o no calificado); que inversiones han realizado compañías privadas sobre la base de una relación determinada con el gobiemo.

Prever que tipo de competencia (injusta, real o imaginada) puede esperarse después de la venta de empresas estatales a una o más empresas.

3. Crear coaliciones del sector privado para apoyar el proceso de privatización:

El sector empresarial debe tener claro cuáles serán los efectos que el proceso de privatización les traerá a ellos, así como los efectos para la sociedad. 
Es importante que exista un programa de educación pública que explique detalladamente los beneficios y problemas que puede ocasionar el proceso.

Luego de conocer los efectos de la privatización, deben fortalecerse las coaliciones del sector privado, a fin de que todos los grupos (representativos de los diferentes sectores) cooperen y trabajen en la búsqueda de mejores oportunidades con el programa.

4. Elaboración de estrategias y pautas del programa:

Este paso debe abarcar el contenido y la forma que tendrán las normas administrativas, considerando los siguientes puntos:

Gradualidad en el avance del proceso de privatización.

Todas las acciones posibles de privatización.

Los factores o criterios a considerar en la elección de objetivos de privatización.

Presentar los posibles incentivos que estimulen la participación de empresas locales en el proceso.

Debe considerarse los problemas de regulación y la aplicación de reglamentos en aspectos económicos y sociales.

\subsection{Etapa II: Elección de objetivos y concretizarlos}

Después de haber desarrollado la primera etapa, se pasa a preparar las acciones específicas de privatización, es decir, a seleccionar los principales objetivos, para luego concretizarlos. Esta etapa desarrolla cuatro aspectos o pasos fundamentales:

1. El primer paso consiste en determinar si se ha hecho un resumen de política de privatización sobre la actividad gubernamental en consideración (si es afirmativo, hay que determinar la utilidad de su análisis $y$ datos en futuros proyectos).

En este paso se requerirá definir las diversas clases de asesoría experta, principalmente en el área escogida, en general sobre contratos y políticas.

En algunos casos será necesario formar un grupo de asesoría permanente, lo cual dependerá de varios factores, entre ellos: el tamaño y la complejidad de la empresa a privatizar; experiencia en el proceso; disponibilidad de confiables datos de gastos y operación, etc. 
2. El segundo paso consiste en hacer un balance organizativo, el cual debe incluir análisis de costos. Este paso considera puntos como los siguientes:

Definir claramente el papel de la organización a privatizar, dentro de gobierno, y la relación con el público al cual sirve:

La organización de la empresa y la extracción de sus empleados. Las prácticas de operación y las instalaciones y equipos requerido para realizar su actividad.

El cumplimiento de los objetivos de producción y desarrollo por parte de la empresa.

Es necesario recopilar, comprobar y analizar datos, los cuales serán la base de un informe escrito; en el cual deben señalarse las principales ventajas potenciales, y los puntos débiles con los que cuenta la empresa, a fin de presentar alternativas que mejoren su actividad.

$\mathrm{El}$ informe antes mencionado, debe incluir los siguientes puntos:

a) La misión y los objetivos

b) La organización con que cuenta

c) El personal

d) La definición de los beneficiarios del servicio

e) Las prácticas de operación

f) La complejidad y servicios existentes y las proyecciones de la cantidad de trabajo

g) Los objetivos de productividad y desarrollo

h) El equipo y las instalaciones

Un informe bien detallado servirá para hacer una planificación técnica eficaz, ya que a través del análisis de cada uno de los elementos se podrán identificar las principales necesidades, problemas, ventajas y fuerzas con las que opera la empresa. Asimismo, estos elementos constituyen los requisitos del proceso de privatización.

3. El tercer paso de esta etapa, consiste en elaborar un balance comercial, en el cual se identifican los gastos de desarrollo de todo el proceso de privatización, para luego determinar su viabilidad. tán:

Entre los principales factores que relaciona este balance comercial es-

a) "Capacidad local con la que se cuenta para realizar sus funciones.

b) Las cargas de capitalización del gobierno y de sector privado.

c) El interés de los negocios locales.

d) Las mejorías de eficiencia. 
e) El aumento de empleos locales.

f) La expansión de oportunidades para empresas locales.

g) La minimización de la eliminación de trabajos." 5

4. El último paso de esta etapa es de carácter estratégico mas que técnico, y consiste en hacer un análisis estratégico comparativo de las diferentes decisiones de privatización. Se deberá considerar los siguientes puntos:

a) Detallar claramente las consecuencias, positivas o negativas, que trae la aplicación de cada opción.

b) Señalar las principales decisiones sobre la forma de como instrumentar el proceso de privatización.

c) Debe considerarse el presupuesto que sea necesario para financiar las mejoras requeridas de capital en la empresa.

d) Además deben tomarse en cuenta los problemas que pueden ocasionar el proceso en cuanto al despido de personal.

Entre las principales opciones estratégicas se menciona: Contratos con el sector privado, vender los derechos de propiedad, dar en arriendo y abandono, etc.

\subsection{Etapa III. Transferencia de la privatización}

Una vez considerada la mejor opción para privatizar una empresa, se pasa a una tercera etapa, en donde se detallan los principales puntos a tomar en cuenta para realizar la transferencia de la privatización. Se presentan a continuación cuatro puntos que facilitarán el éxito del proceso.

1) En primer lugar debe estimarse el valor de la empresa:

- Definir el valor real de la empresa y el valor en libros.

- Realizar los inventarios de pasivos y activos mediante auditorías, proyecciones financieras, obligaciones, etc., a fin de determinar la situación económica de la empresa.

2) Luego de valorar la empresa, se prosigue a un segundo paso, el cual consiste en establecer las condiciones bajo las cuales se presentará la privatización, así como también a solicitar la transferencia. Debe considerarse lo siguiente:

- Preparar toda la documentación legal necesaria para realizar las transacciones. 
- Solicitar autorización para realizar la transferencia.

- Preparar las bases bajo las cuales se hará la transferencia.

3) En tercer lugar, se debe evaluar y elegir al comprador, considerando los puntos siguientes:

- Selección detallada del comprador, que puede ser nacional o extranjero.

- Notificar quienes serán los compradores, los cuales deberán gozar de una buena solvencia.

- Fijar las condiciones de promoción bajo las cuales se realizará la transferencia.

- Recepción de ofertas.

4) En último lugar, se procede a realizar la negociación y la transferencia o venta de la empresa. Después de ser aprobada la transferencia, se analizan las diferentes ofertas y se notifican los resultados a los que se llega; y se procede a firmar la documentación necesaria entre el gobierno y el comprador, realizando la transferencia.

\subsection{Etapa IV. Vigilar los resultados}

Esta última etapa es de vital importancia, ya que es aquí donde se debe incluir el carácter legal, bajo el cual se desarrollará el proceso de privatización. El fundamento legal debe garantizar que el proceso goce de credibilidad, basada en la transparencia y equidad del proceso.

Son dos los puntos principales a tomar en cuenta en esta etapa:

1) Deben establecerse los mecanismos regulatorios y de supervisión, necesarios para realizar un proceso de privatización integro. Este paso debe incluir una ley de privatización y un ente de regulación que rija el proceso.

2) Un segundo punto a considerar, consiste en vigilar el comportamiento que tiene y debería seguir el proceso de privatización, con el objetivo de que goce de credibilidad.

De esta forma se han listado las principales etapas que pueden seguirse durante la implementación de todo proceso de privatización. Estas etapas han sido aplicadas en las experiencias de privatización de otros países, con el propósito de facilitar y garantizar un proceso de privatización efectivo. De lo contrario se puede concluir que "la privatización sin política, procedimientos y sin un equipo comprometido 
y competente, está condenada al fracaso"6.

Estas etapas y pasos pueden realizarse simultaneamente en el tiempo ya que, como ejemplo, antes de realizar la íransferencia, debería existir un marco regulatorio.

Los preparativos para la privatización requieren de la educación, organización y movilización de cuatro grupos que deben trabajar juntos. Cada uno debe comprender los gastos, la productividad, la capitalización y otros temas actuales que tienen entre sí las empresas que posee y opera el estado.

Los cuatro grupos que pueden decidir el futuro de un programa de privatización son:

1) El grupo político: el dirigente político ejecutivo y legislativo (parlamentario).

2) El público: los consumidores y destinatarios de los productos y servicios públicos.

3) Los empleados y directores gubernamentales: el grupo ajeno al dirigente político, por lo común, los profesionales del ramo civil, supervisores y trabajadores no calificados. Como ejecutores de la labor del estado, conforman el grupo que más directamente afecta la privatización.

4) La comunidad comercial: los intereses comerciales expatriados o locales con la mayor disposición y capacidad para adquirir, arrendar o manejar actividades que tiene $y / u$ opera el gobierno.

\section{Obstáculos y consecuencias de la privatización}

\subsection{Los obstáculos}

Una vez conocidos los pasos y etapas de la privatización, es necesario tomar en cuenta qué obstáculos se pueden presentar en el proceso. De manera general se presentan los siguientes:

a) Obstáculos de carácter institucional como:

i) Poco desarrollo de la bolsa de valores

ii) Sistemas financieros débiles

b) Dificultades financieras en el país

c) Dificultades para la implementación de los programas de privatización

d) Dificultades políticas 
Entre los principales obstáculos para el proceso de privatización en países subdesarrollados

a) La privatización en la mayoría de los casos se debe a presiones económicas insostenibles para seguir subvencionando a empresas estatales.

b) Desconocimiento sobre como iniciar el proceso

c) El sector privado no tiene el suficiente desarrollo que proporcione la inversión doméstica necesaria para comprar empresas estatales, y pueden negarse las ventas a inversionistas privados del extranjero cuando se crea que llevan a una pérdida de control sobre el desarrollo industrial nacional.

d) Falta de mercados de capital: especialmente los legales y los servicios de crédito severamente restringidos accesibles al sector privado.

e) No hay una estimación precisa del tamaño del sector público. Existe falta de coordinación entre los ministerios, lo cual lleva al estado a invertir sin ejercer control.

f) Muchas veces lo que se quiere vender son empresas que productiva y financieramente no marchan bien y que presentan un valor en libros muy diferentes a su valor comercial, circunstancia que en sí representa un problema en la agilización de la venta de activos.

g) El apoyo político interno para la privatización es reducido en la mayoría de los países subdesarrollados.

h) Se oponen los intelectuales, porque lo ven como una venta de los bienes del país a los grupos de poder.

i) No habrá suficientes proveedores para facilitar la competencia: pocas empresas entran al campo, lo cual creará situación monopólica u oligopólica (privada) en prejuicio del consumidor.

j) Se incluye también una serie de problemas tales como:

* Desconfianza en el funcionamiento del mercado.

* Desconfianza en el individuo.

* exigencias políticas.

* Problemas de valorización.

* Mal negocio.

* Falta de financiamiento.

* Costo social al sector privado puede implicar desempleo o tam- 
bién incremento de precios y tarifas, y congelamiento de salarios.

\subsection{Consecuencias de la privatización}

El estado en el corto plazo resuelve el problema del déficit fiscal, pero no se presenta una solución en el largo plazo.

Se presenta el problema de hasta que punto permitir la inversión extranjera.

Mayor concentración del ingreso o desigual distribución.

Descuido de inversión en áreas necesitadas del servicio (rural o interior).

Desnacionalización.

Tendencia a la terciarización.

Dado el incremento del ingreso, poca transparencia

\section{Formas o modos de privatización}

Es de utilidad conocer las diversas formas o modos de privatización, para tener más elementos de juicio al tratar de elegir la mejor opción.

Existen ocho formas de privatizar empresas estatales, aunque también hay combinaciones de estas.

\section{1) Venderlas por acciones en forma de amplia distribución}

Esto es fácil bajo las siguientes condiciones:

a) Si existe una extensa clase media con ahorros considerables

b) Si las compañías son bien conocidas y sólidas

c) Si existe un mercado que funcione bien.

Sin embargo estos aspectos no se dan en países en desarrollo, por lo cual es un método más fácil para los países desarrollados, por ejemplo Francia, Inglaterra, Alemania.

Sin embargo puede darse en países subdesarrollados si :

- Existe un buen mercado

- Existe biena publicidad

Ejemplo Jamaica con bancos; Turquía con televisión.

\section{2) Venta de acciones a empleados}

Es un método socialmente deseable, en los países subdesarrollados 
donde los empleados no tiene ahorros para comprar acciones, esto puede resolverse mediante varias formas:

a) Un descuento en las acciones que compren

b) Pago a plazos de las acciones

c) Participación en las utilidades, utilizándola para compra de acciones Sin embargo, hay que tomar en cuenta:

i) Los casos de negocios riesgosos

ii) La actitud de sindicatos y trabajadores debe ser positiva

\section{3) Venta a empresarios nacionales}

Ventajas:

- Los compradores cuentan con experiencia administrativa y con recursos para hacer inversiones necesarias.

Desventajas:

- Hay más concentración de capital

- Al gobierno se le acusa de favoritismo

Transparencia:

Esta condición necesaria para todos los modos de privatización, significa que la venta no es resultado de acuerdos secretos

Cuando el Estado vende sus empresas a grupos de inversionistas, el riesgo empresarial debe transferirse totalmente, y deben ser suspendidos todos los privilegios.

\section{4) Venta a empresarios extranjeros}

Inconveniente:

- Se crea desnacionalización

- Si la venta es causa de temores por parte de políticos

Ventajoso cuando:

- Comprador genere mercados sustanciales de exportación

- Comprador introduzca nuevas tecnologías

- Comprador ofrece y paga precio alto. 
5) Alquiler de la empresa en lugar de venta

Este método no significa privatización total

- El Estado sólo se deshace de la operación de la empresa alquilándola a una compañía privada, pero permaneciendo como su propietario.

- Este método difícilmente se aplica a empresas industriales

- El método es más aplicable a empresas de servicios donde se necesita capital intensivo.

\section{6) Apertura a la competencia de mercado}

Consiste más que todo en someter a las empresas del estado a la prueba del mercado competitivo.

- Permite el ingreso de empresas extranjeras

- Elimina privilegios y subsidios

- Desde el punto de vista político es más fácil para los países subdesarrollados.

- El gobierno no pierde porque las compañías privadas suplen bien el mercado impidiendo la carestía.

- Si la empresa estatal se extingue porque no pasó la prueba de la competencia no hay quejas populares, y si pasa la prueba se hace eficiente y sobrevive.

7) Disolución formal de las empresas estatales

- La empresa no se vende pues nadie quiere comprarla

- El desequilibrio de la empresa no puede ser mejorado en el corto plazo

- La inversión original fue un error

- El tesoro público tiene un ingreso en efectivo

- Hay que tener en cuenta mantener empleos improductivos.

\section{8) Contratación de servicios privados}

Para la administración u operación de ciertas labores realizadas ahora dentro de empresas públicas; tales como mantenimiento de automotores, limpieza de oficinas, administración hospitalaria, instalación de equipos, etc. 


\section{Propuesta alternativa para la privatización de ANTEL}

La privatización de las empresas públicas en El Salvador es un proceso que no ha sido ampliamente discutido. La primera y segunda etapa del proceso se interrumpio con el último cambio de gobierno, tratando de avanzar directamente a la etapa de la transferencia.

Esto ha traido como consecuencia que, como lo han declarado funcionarios como el Comisionado Presidencial para la Privatización o el Presidente de ANTEL, aún no se ha definido la forma en que se va a privatizar. Unicamente se ha decidido que este año deben ser privatizadas las grandes empresas públicas. Se ha decidido transferir las propiedades, programandose en el tiempo, sin aún haber definido las consecuencias económicas y sociales.

Pero al margen de la conveniencia o no de la privatización, debe aceptarse que el gobierno está decidido a implementarla. En consecuencia, se hace necesaria la propuesta de una alternativa a la simple venta sin ningún control, tal como la ha presentado el Comisionado Presidencial.

Como una condición imprescindible previa a la venta en sí de los activos estatales, debe asegurarse el respeto de los principios constitucionales. Esto es, que el bienestar de la sociedad prive sobre el bienestar individual.

Debe crearse el Ente Regulador del sector, con suficiente autoridad y autonomía para proterger los derechos de los usuarios ante los nuevos operadores. Deben establecerse claramente las "reglas del juego", es decir, las condiciones bajo las cuales se realizará la privatización: Metas de inversión, de penetración, regulaciones técnicas de la explotación, condiciones tarifarias, no intervención de las comunicaciones, libre acceso a los servicios, control antimonopolico, etc.

Debe modificarse la Ley de los Servicios de Telecomunicaciones, para posibilitar la liberalización y desregulación del sector. Esta legislación debe contemplar la normalización del sector y el cambio de la figura jurídica de ANTEL de empresa pública a empresa privada.

Deben crearse los mecanismos regulatorios y de supervisión para asegurarse que las empresas cumplan efectivamente las condiciones impuestas en las privatización, y asegurar la protección del consumidor y de los accionistas minoritarios.

Una vez establecidas las condiciones básica legales y normativas, debe definirse la forma de privatizar, el proceso y su programación, así como los aspectos de transparencia en el uso de los fondos provenientes del proceso. 
Como se ha definido anteriormente, el problema no es que el Estado sea el propietario de las acciones. Los argumentos hacia la privatización se orientan más a una cuestión de eficiencia y burocracia en la toma de decisiones empresariales. En este contexto, puede elegirse una forma de privatización que posibilite una administración con criterio empresarial; elimine las trabas legales que imponen el carácter estatal de las empresas; proteja los ingresos futuros del Estado; amplíe el acceso a la propiedad de las empresas; y provea fondos frescos para los programas sociales.

La solución se orientaría hacia una liberalización inmediata de los servicios de telefonía diferentes a la telefonía básica, como es el caso de la telefonía celular.

Se convertiría la empresa estatal de comunicaciones en una empresa de capital accionario, cuyo accionista principal sería el Estado (en un $51 \%$ ). Una parte de las acciones se daría como opción de compra preferencial a los empleados (en un 14\%), financiadas, a precios de libros y pagaderas con el pasivo laboral. El resto de las acciones (35\%)se vendería a través de la bolsa de valores, en emisiones sucesivas destinadas a empleados estatales (5\%), pequeños accionistas (5\%), y el resto sin restricciones $(25 \%)$.

La administración de la nueva empresa debe ser contratada como un servicio de una empresa internacional especializada, tal como se contratan otros servicios profesionales. El pago de los servicios de administración será en base a un porcentaje de las utilidades del ejercicio, lo que permitirá que los administradores tomen sus desiciones en base a criterios que busquen maximizar la utilidad, dentro de las restricciones impuestas por las condiciones de privatización. El período de contratación sería tres años, para permitir evaluar la maduración de los nuevos proyectos, y el seguimiento de los planes mínimos de inversión.

\section{BIBLIOGRAFÍA}

Barba, Jaime y Lungo, Mario (compiladores): Estado y Mercado. Itsmo Editores. San Salvador, 1995.

Barré, R.: Economie Polítique. Vol. I. PMF. París. 1994

CEPAL: La crisis de la empresa pública, las privatizaciones y la equidad social. Serie Reformas de politica Pública. Santiago de Chile, 1994.

FUSADES: Soluciones Descentralizadas / Privadas a problemas Públicos. Resumen de seminario realizado el 17 y 18 de mayo de 1994.

FUSADES: Hacia una economia de mercado en El Salvador: Bases para una nueva estratégia de desarrollo económico y social. Mayo de 1989.

Geiger, Erwin P.: Privatización y Política Económica.

Hanke, Steve H.: Privatización y Desarrollo. Editorial TRILLAS, México, 1989.

Hinds, Manuel: El Salvador: What's now?. Abril de 1993. mimeo. 
Ministerio de Hacienda de El Salvador: Privatización: Un marco de referencia para la formulación de las políticas y el análisis.

Montoro, Xabier Arrizabalo: Resultados económicos de la dictadura en Chile (1973-1990). Documento de trabajo, Instituto Internacional de Desarrollo (ID) 1993.

Olano Rafaél y Moráles, Oscar: Interpretación Socioeconómica de la Política Neoliberal. Revista Realidad Económico - Social No. 23, septiembre - octubre de 1991.

PNUD: Informe sobre Desarrollo Humano. Publicado para el programa de las Naciones Unidas por el Fondo de Cultura Económica. 1994.

Varios: Etica, Economía, Politica y Pobreza, el desafío crucial para Latinoamérica. CIEDIA de la furıdación Konrad Adenauer Stittung. San José de Bogotá, Colombia.

\section{Notas}

1. La Eficiencia Económica y los Procesos de Privatización. INCAE.

2. Privatización: Un marco de referencia para la formulación de políticas y análisis. Ministerio de Hacienda de El SAlvador, pág. 4.

3. Privatización y Política Económica. E. Geiger.

4. Informe del seminario sobre privatización y liberalización, celebrado del 12 al 14 de noviembre de 1987. INCAE, pág. 11.

5. Hanke, Steve H.: Privatización y desarrollo. Editorial Trillas. México, D.F., $1^{\text {a }}$ edición, 1989. Pág. 68.

6. Ibid. pág. 71 . 